\title{
RISK ANALYSIS AND MANAGEMENT OF MOORED SHIPS IN PORTS
}

\author{
Liliana V. Pinheiro \\ LNEC - National Laboratory for Civil Engineering \\ Lisbon, Portugal
}

\author{
Conceição J. E. M. Fortes \\ LNEC - National Laboratory for Civil Engineering \\ Lisbon, Portugal
}

\author{
João A. Santos \\ ISEL - IPL, Instituto Superior de Engenharia de Lisboa, \\ Instituto Politécnico de Lisboa, Lisbon, Portugal \\ CENTEC - Centre for Marine Technology and Ocean \\ Engineering, University of Lisbon, Lisbon, Portugal
}

\section{ABSTRACT}

The risks associated with mooring of ships are a major concern for port and maritime authorities.

Sea waves and extreme weather conditions can lead to excessive movements of vessels and mooring loads affecting the safety of ships, cargo, passengers, crew or port infrastructures.

Normally, port activities such as ships' approach manoeuvres and loading/unloading operations, are conditioned or suspended based solely on weather or wave forecasts, causing large economic losses. Nevertheless, it has been shown that some of the most hazardous events with moored ships happen on days with mild sea and wind conditions, being the culprit long waves and resonance phenomena. Bad weather conditions can be managed with an appropriate or reinforced mooring arrangement.

A correct risk assessment must be based on the movements of the ship and on the mooring loads, taking into account all the moored ship's system.

In this paper, the development of a forecast and warning system based on the assessment of risks associated with moored ships in port areas, SWAMS ALERT, is detailed.

This modular system can be scaled and adapted to any port, providing decision-makers with accurate and complete information on the behaviour of moored ships, movements and mooring loads, allowing a better planning and integrated management of port areas.

\section{INTRODUCTION}

The concept of Risk Management (RM) integrates: risk analysis; risk mitigation and emergency response, recovery and reconstruction after a hazardous event (Faber, 2007). Taubenböck et al., (2008) defines risk as the interaction between hazard and vulnerability and the RM cycle as the basis for sustainable development. A RM cycle is a series of steps divided in two blocks: before and after a disaster event occurs. Before a disaster event occurs all available data must be gathered to form an information database. Then assess people and environment's exposure, susceptibility and coping capacity to a given disaster event. Devise a prevention plan and a reaction plan. Then it is possible to assess the vulnerability of those elements to that particular disaster. To measure the hazard itself one must define its type, intensity and probability of occurrence. After a disaster occurs, the reaction plan must be put into action and if needed rehabilitation and reconstruction measures must be undertaken as fast and as effectively as possible.

Several authors and their teams have conducted research on the integrated analysis of risks factors on port management, (e.g., Mokhtari et al. (2012), Chang et al. (2014)) and addressing safety and security risks in more or less inclusive terms (e.g., Talley, 1996; Notteboom, 2006; Husdal and Bråthen, 2010; Wang et al., 2014, Chang et al. (2014)).

Port Risk Management involves the identification of uncertainty sources completely covering the range of possibilities that can in any way influence performance of port activities. Because they are so numerous, they have to be broken down into broad categories, Ward (2005).

For instance, Mokhtari et al. (2012), divided risk factors into six categories:
1. Safety;
2. Security;
3. Pollution; 


\section{Legal; \\ 5. Human error related; \\ 6. Technical.}

Chang et al. (2014) found that the top 3 factors associated with safety and security were: (1) pirate or terrorist attacks; (2) ship or quay damage due to improper berth operations and (3) transporting dangerous goods. Apart from the first risk factor, the other two are largely hampered by environmental actions.

Environmental actions, such as extreme weather conditions, tsunamis and climate change affect the safety of ships and port infrastructures and consequently people and goods in their vicinities. From an engineering point of view, these actions and their effects can be somehow assessed, predicted and quantified. Berthing, mooring and terminal operations could be adjusted to forecasted weather and sea conditions. So risk could be managed a priori and reduced.

Dangerous events associated to sea-wave action are common. Especially, the risks associated with navigation and mooring of ships are a major concern for port and maritime authorities. Sea waves can disturb and even disrupt port activities such as ships' approach manoeuvres, loading and unloading. In fact, excessive movements of vessels due to waves can put at risk the safety of people, goods, port infrastructures and the ships themselves.

Yip (2008), performed an extensive study on marine accidents, recorded in 2001-2005, within Hong Kong port, which, for many years, was ranked as the world's busiest port. $\mathrm{He}$ found that collision accidents are the most common incidents when port traffic is heavy. Almost $67 \%$ of all accidents were impacts: "Collision" and "Contact". 12\% of all accidents occurred when the ship was moored.

Ports and harbours are especially vulnerable to climate changes that continuously lead to sea level rise and more frequent and intense storm events, hampering port operations, the regular movement of goods and people to/from these ports and the safety of port structures. Disaster forecast and management systems do increase operation and navigation safety in emergency situations caused by natural hazards but are not widely available nor tailored to specific ports.

This calls for innovative tools for risks prevention and emergency and crisis management. They enable a better planning, monitoring and surveillance in emergency situations. Moreover, since such situations are mainly caused by incidentsea waves, a phenomenon that, nowadays, can be forecast with accuracy up to 36 hours in advance, it is possible to implement a forecast system for the effects of sea-wave action on port navigation, infrastructure and operation, thus increasing the port system resilience to disaster events.

In this context, LNEC has developed a forecasting, warning and risk assessment system for overtopping and flooding events in coastal and port areas, called HIDRALERTA (Sabino et al., 2015). This system was tested in the port of Praia da Vitória, in the Azorean island of Terceira and in the Costa da Caparica area, Almada.

To extend the functionality of this system to the forecast, warning and risk assessment of dangerous events associated with the navigation in port areas and the behavior of moored ships, a new system called SWAMS ALERT was developed.

SWAMS ALERT was designed as disaster forecast and management system that forecasts, identifies and monitors emergency situations related to moored ships in ports and harbours, sends early warning messages to responsible entities and activates emergency plans. This system can be fine-tuned to a specific port, thus becoming a valuable tool to help in the selection of docking and mooring devices.

The system consists of four modules: I - Waves characteristics; II - Port operations; III - Risk assessment and IV - Warning system. The system was developed using Python scripts and implemented on a fully interactive user-friendly web platform.

The SWAMS ALERT system uses measured and forecast sea-wave characteristics to determine their effects in terms of excessive vertical movements of a manoeuvring ship that enters or leaves a harbour basin or in terms of forces on mooring lines and fenders as well as of motions of a ship moored at a quay. To do so, the system uses a set of numerical models. The comparison of the computed values of the relevant variables with pre-set maximum values enables:

i) Real-time identification of emergency situations or situations where the safety of port operations is at risk and to issue warnings to the responsible authorities;

ii) Issuing warnings to the responsible authorities and to port stakeholders.

iii) Construction of risk maps, considering long time series of measured or forecast sea waves or predefined scenarios associated with climate change or extreme events.

This paper describes the SWAMS ALERT system and illustrates how it applies to a real port.

\section{NOMENCLATURE}

$\mathrm{H}_{\mathrm{s}} \quad$ significant wave height, $\mathrm{m}$

$\mathrm{T}_{\mathrm{m}} \quad$ average wave period, $\mathrm{s}$

$\mathrm{T}_{\mathrm{p}} \quad$ peak wave period, $\mathrm{s}$

\section{Greek symbols}

$\theta_{\mathrm{m}} \quad$ average wave direction, ${ }^{\circ}$

\section{Subscripts}

$\begin{array}{ll}\mathrm{m} & \text { average } \\ \mathrm{p} & \text { peak } \\ \mathrm{s} & \text { significant }\end{array}$

\section{PORT MANAGEMENT}

Port competitiveness is a direct result of its efficiency rates, which can be maximized by reducing costs and increasing operationality and ensuring the highest level of service, always safeguarding overall safety. Effective portoperation management and planning can set one port aside from 
its competitors. Moreover, risk management guidelines specifically designed for a given port and all its structures are critical to avoid accidents and provide a proper response when they do occur.

To mitigate the risk of accidents in a port environment, it is crucial to rely on science-based integrated risk management.

Forecast, warning and alert systems are a way of providing an integrated decision-support framework for port management.

The daily outputs of a warning system that can predict moored ships movements and forces do provide to port authorities valuable information for timely decisions on the following 3-day port management period.

This reduces ports' vulnerability and increases their resilience and planning capacity to respond to emergency situations, focusing on port operations such as docking and mooring. In addition, such system enables greater access to information and communication as well as specifically targeted information regarding a particular harbour or dock.

Online and mobile applications do help to raise awareness of the public and of key stakeholders to sea-wave effects on moored ships in ports and to the risks associated with natural extreme events.

Defining a single solution that is suitable for all ports and making it flexible and scalable is still the major challenge for this system. There are several emergency situations to be considered in the development of the disaster forecast and management system. In this paper the focus is on excessive movements of moored ships and excessive forces on mooring lines and fenders.

The initial data that drives the whole system include wave and wind forecasts whose accuracy and robustness are increasingly enhanced as the numerical models become more complex and reliable.

\section{SEA-WAVES FORECAST}

The purpose of Module $\mathrm{I}$ is to evaluate sea-wave characteristics - the significant wave height $\left(\mathrm{H}_{\mathrm{s}}\right)$, wave period (average, $T_{m}$, or peak, $\left.T_{p}\right)$ and average direction $\left(\theta_{m}\right)$ - along its propagation from offshore up to coastal and port areas. These sea wave characteristics can be forecast 72 hours in advance (with results every 3 hours) or can be obtained from historical data.

The sea-wave characteristics along the coast or within a port can be obtained by means of one or more numerical models for sea-wave generation and propagation. The type and number of numerical models to be applied depend on the study region characteristics (for example, its size) and on the phenomena involved in the sea-wave propagation.

In the SWAMS ALERT system, the following models for sea-wave propagation are used:

- WAM, third generation ocean wave prediction model (Hasselman, 1988);

- SWAN, nonlinear spectral wave generation and propagation model (Booij et al., 1999);
- DREAMS, linear wave propagation model for sheltered areas DREAMS (Fortes, 2002);

- $\quad$ BOUSS-WMH (Boussinesq Wave Model for Harbors) is a finite element model for nonlinear wave propagation near shore and wave penetration in harbors (Pinheiro et al. 2012).

Predictions of wind data and sea level of astronomical tide are obtained from NAVGEM, (Whitcomb, 2012) and XTide, (Flater, 2016) models, respectively.

\section{MOORED SHIP RESPONSE TO WAVES AND WIND}

Module II deals with two potential hazards related to port operations: manoeuvring and moored ships. Excessive movement, particularly in the vertical plane, when a ship manoeuvres to enter or leave a port can lead to emergency situations. The same applies to excessive moored ship motions, although restricted by the mooring system, since it can lead to interruption of loading and unloading operations as well as to increased risk of rupture of a mooring system element (mooring line or fender) or ship collision with port infrastructure. At this stage, only the evaluation of the risk associated to excessive moored ship motions is implemented in the SWAMS ALERT system.

The determination of the movements of a ship moored to a berth subjected to incident sea-waves is performed using the numerical package MOORNAV, Santos (1994). This package is made of two numerical models and a set of routines that makes the connection between them:

- WAMIT, Korsemeyer et al. (1988), which solves, in the frequency domain, radiation and diffraction problems of the interaction between a free-floating body and the sea waves incident on it;

- BAS, Mynett et al. (1985), which assembles and solves, in the time domain, the equations of motion of a ship moored at the berth, by considering the time series of the forces due to the incident waves on the ship, the impulse response function of the ship and the constitutive relations of mooring system components (mooring lines and fenders).

The WAMIT model, was developed at the Department of Ocean Engineering of the Massachusetts Institute of Technology and uses a panel method for solving in the frequency domain radiation and diffraction problems of a freefloating body. This model uses the second Green identity to determine the intensity of the source and dipole distributions in the panels of the hull's wetted surface discretization. The forces along each of the six degrees of freedom of the ship motion are determined for regular incident waves that hit the ship.

The BAS model uses the impulse response, the mass (including added mass) and hydrostatic restoration matrices, together with the time series of the forces exerted by the waves on the ship and the constitutive relations of the mooring system elements (mooring lines and fenders) to set up the equations of motion of the moored ship: 


$$
\begin{gathered}
\sum_{j=1}^{6}\left[\left(M_{k j}+m_{k j}\right) \ddot{X}_{j}(t)+\int_{-\infty}^{t} K_{k j}(t-\tau) \dot{X}_{j}(\tau) d \tau+C_{k j} X_{j}(t)\right]=F_{k}^{e x t}(t) \\
F_{k}^{e x t}(t)=F_{k}^{d}(t)+F_{k}^{w}(t)+F_{k}^{c}(t)+F_{k}^{m}(t)+F_{k}^{f}(t)
\end{gathered}
$$

where $M$ and $C$ are respectively the mass and the hydrostatic restitution matrices of the ship. $m$ and $K$ are respectively the added mass and the retardation function matrices. $m_{k j}$ is the force along the generalized coordinate $k$ due to unit acceleration of the ship along coordinate $j$ and $K_{k j}(\tau)$ is the time series of the force along $k$ due to an impulsive velocity along $j$ at time $t=0 . F_{k}^{e x t}(t)$ represents the time series of the external forces: $F_{k}^{d}$-wave diffraction force, $F_{k}^{m}$ - mooring lines forces, $F_{k}^{f}$ - fenders forces, $F_{k}^{w}(t)$ - wind forces and $F_{k}^{c}$. - currents forces.

The forces due to mooring lines and fenders can be determined from their constitutive relations. The wave diffraction forces result from a synthetic time series generated from the characteristic values of the wave field obtained with DREAMS model.

Strictly speaking, this is a set of six equations whose solutions are the time series of the ship movements along each of her six degrees of freedom, $X_{j}(t)$ as well as of the forces in the mooring lines and fenders.

\section{RISK ANALISYS}

The objective of the risk analysis module is the evaluation of the moored ships' risk. Risk assessment is based upon the concept of risk level as the product of the probability level, associated with the exceedance probability of a pre-set threshold for the movements' amplitude, velocities and mooring line forces, by the consequences level associated to such exceedance (Raposeiro, et al., 2010).

Therefore, the procedure for risk assessment is:

a) evaluate the nature of the activities that take place in the port terminal where the ship is moored and the impact of its movements on the terminal's operationality and on the safety of the ship, of the infrastructure and of the people;

b) establish the thresholds for the allowable movements for each type of ship and activity, as well as the forces on mooring lines, based on the consequences levels established for each one;

c) Determine the probability of exceedance of these thresholds;

d) Assess the risk level.

The thresholds for the allowable mean/max movements are set based on existing recommendations, which take into account the nature of the activities, the characteristics of the ship and the need to ensure the safety of people and infrastructures. The consequences of exceeding those thresholds have been estimated using a methodology that allows a simple qualitative evaluation of the consequence level associated with hazardous events.

The adopted values in this paper are based on several organizations concerned with maritime and port activities that have issued recommendations to limit wave heights, movement amplitudes (PIANC 1995), Table 1, velocity amplitudes of ship motions, (Elzinga et al., 1992), Table 2, as well as tensions in the mooring system elements (OCIMF, 1992, PIANC 1995), Table 3. Evidently, these thresholds can be set case by case to reflect each port administration internal criteria and rules.

The limits to horizontal, vertical, or rotational movements depend on the associated consequences. PIANC has established working groups issuing regular reports with recommendations on moored ships maximum movements. There are operational limits, above which the cargo handling is conditioned or even impossible and safety limits, above which there is a risk to people, property or the structures.

Regarding the limits on the mooring system forces, OCIMF recommends that they must be distributed evenly by each mooring line and not exceed $55 \%$ of Maximum Breaking Load (MBL).

Recently, a PIANC working group updated the guidelines for the maximum movements of moored container ships that ensure efficient unloading operations (PIANC, 2012). In that report, it was concluded that for large container ships, limiting the surge motion is essential, since the cranes have limited translation margins. The same report states that when the surge motion is kept within the prescribed limits, the motions along the other degrees of freedom are also within acceptable limits.

Pre-set limits to the moored ships motions are defined to ensure the minimum operational conditions and the safety of the port terminal (PIANC, 1995). Safety limits can and should also be defined for the maximum forces in the elements of the mooring system (mooring lines and fenders) of the studied ship, since their breakage may lead to considerable damage. These limits are based on the characteristics of the ship and of its mooring lines and fenders.

Table 1. Consequence levels of exceeding movement amplitude.

\begin{tabular}{lcccccc}
\hline Consequence & Level & $\begin{array}{c}\text { Surge } \\
(\mathrm{m})\end{array}$ & $\begin{array}{c}\text { Sway } \\
(\mathrm{m})\end{array}$ & $\begin{array}{c}\text { Heave } \\
(\mathrm{m})\end{array}$ & $\begin{array}{c}\text { Roll } \\
\left({ }^{\circ}\right)\end{array}$ & $\begin{array}{c}\text { Pitch/Yaw } \\
\left({ }^{\circ}\right)\end{array}$ \\
\hline Insignificant & 0 & 0.1 & 0.1 & 0.1 & 0.5 & 0.1 \\
Mild & 1 & 0.3 & 0.2 & 0.2 & 1.0 & 0.3 \\
Serious & 2 & 0.4 & 0.25 & 0.3 & 1.3 & 0.4 \\
Critical & 3 & 0.5 & 0.3 & 0.4 & 1.5 & 0.5 \\
\hline
\end{tabular}

Table 2. Consequence levels of exceeding movement velocities.

\begin{tabular}{lllllll}
\hline Consequence & Level & $\begin{array}{l}\text { Surge } \\
(\mathrm{m} / \mathrm{s})\end{array}$ & $\begin{array}{l}\text { Sway } \\
(\mathrm{m} / \mathrm{s})\end{array}$ & $\begin{array}{l}\text { Heave } \\
(\mathrm{m} / \mathrm{s})\end{array}$ & $\begin{array}{l}\text { Roll } \\
(\% / \mathrm{s})\end{array}$ & $\begin{array}{l}\text { Pitch/Yaw } \\
(\% / \mathrm{s})\end{array}$ \\
\hline Insignificant & 0 & 0.1 & 0.1 & 0.1 & 1.0 & 1.0 \\
Mild & 1 & 0.3 & 0.3 & 0.3 & 1.5 & 1.5 \\
Serious & 2 & 0.45 & 0.45 & 0.45 & 1.8 & 1.8 \\
Critical & 3 & 0.6 & 0.6 & 0.6 & 2.0 & 2.0 \\
\hline
\end{tabular}

Table 3. Consequence levels of exceeding forces on mooring system. 


\begin{tabular}{llll}
\hline Consequence & Level & $\begin{array}{l}\text { Mooring lines } \\
(\mathrm{kN})\end{array}$ & $\begin{array}{l}\text { Fenders } \\
(\mathrm{kN})\end{array}$ \\
\hline Insignificant & 0 & 100 & 1500 \\
Mild & 1 & 400 & 2000 \\
Serious & 2 & 600 & 2500 \\
Critical & 3 & 900 & 4500 \\
\hline
\end{tabular}

In order to determine the probability of exceedance of these thresholds a time series analysis is performed on each of the time series obtained from the simulation models, namely, six degrees of freedom movement amplitudes, six degrees of freedom movement velocities, mooring lines forces and fenders forces. Five hundred seconds time series are produced for each of these variables. Each time series undergoes a Fourier transform and a power density spectrum is obtained. From this spectrum, statistical information can be derived from spectral moments. One dimensional spectral moments are defined in Eq. 1. The length of the power spectrum is $\mathrm{N}$, and the sampling interval is $\Delta t$.

$$
m_{n}=\frac{1}{N} \sum_{l=1}^{N} S(l)(l / N \Delta t)^{n}
$$

The different moments each have a statistical interpretation, the zero-order spectral moment is the average of the values in the interval 1 to $\mathrm{N}$, and is proportional to the mean energy in that interval:

$$
\mathrm{m}_{0}=\frac{1}{\mathrm{~N}} \sum_{\mathrm{l}=1}^{\mathrm{N}} \mathrm{S}(\mathrm{l})
$$

Since these variables are a direct result of wave action, the statistical distribution is assumed to be a Rayleigh distribution (Longuet-Higgins, 1952). So, the mean value is given by:

$$
\overline{\mathrm{H}}=2.507 \sqrt{\mathrm{m}_{0}}
$$

Note that the variable $H=(X, U, F)$, can be movements $(X)$, velocities $(U)$ or Forces $(F)$.

The probability density function (PDF) is then calculated as:

$$
\operatorname{PDF}=\frac{\mathrm{x}}{\sigma^{2}} \mathrm{e}^{\left(-\mathrm{x}^{2} / 2 \sigma^{2}\right)}, \text { where } \sigma=\frac{\overline{\mathrm{H}}}{\sqrt{\frac{\pi}{2}}}
$$

Other statistical parameters can be calculated as well, such as the root mean square value, $H_{r m s}$, the significant value, i.e. the average of the higher third of records, $H_{s}$, the $10^{\text {th }}$ percentile, $H_{10}$, or the $100^{\text {th }}$ percentile, $H_{100}$, Fig. 1 .

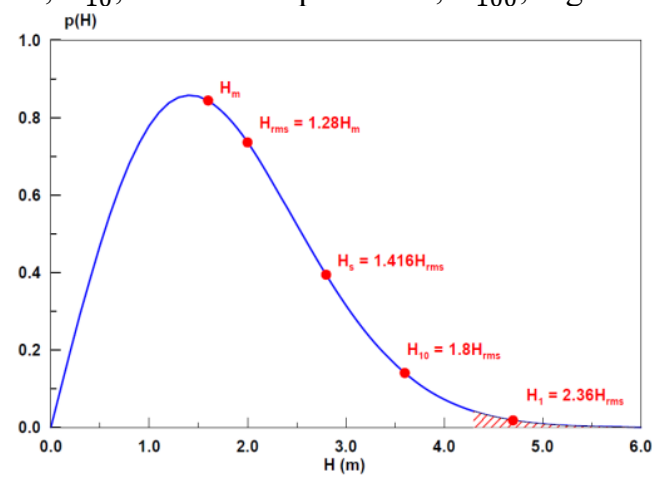

Fig. 1. Probability density function.

The exceedance probability is given by:

$$
\mathrm{P}(\mathrm{H}>\mathrm{x})=\mathrm{e}^{\left(-\mathrm{x}^{2} / 2 \sigma^{2}\right)}
$$

and is ranked as Rare $(\mathrm{P}<0.001 \%)$, Unlikely $(\mathrm{P}<0.1 \%)$, Possible $(0.1 \%<\mathrm{P}<10 \%)$ and Likely $(\mathrm{P}>10 \%)$. The result of multiplying

\begin{tabular}{|c|c|c|c|c|c|c|}
\hline \multirow{3}{*}{\multicolumn{2}{|c|}{$\begin{array}{l}\text { Exceedance } \\
\text { Probability levels }\end{array}$}} & & \multicolumn{4}{|c|}{ Consequence levels } \\
\hline & & & \multirow{2}{*}{$\begin{array}{r}\text { Ins. } \\
0\end{array}$} & \multirow{2}{*}{$\begin{array}{r}\text { Mild } \\
1 \\
\end{array}$} & \multirow{2}{*}{$\begin{array}{c}\text { Serious } \\
2 \\
\end{array}$} & \multirow{3}{*}{$\begin{array}{c}\text { Critical } \\
3 \\
\end{array}$} \\
\hline & & & & & & \\
\hline Rare & $\mathrm{P}<0.001 \%$ & 0 & 0 & 0 & 0 & \\
\hline Unlikely & $\mathrm{P}<0.1 \%$ & 1 & 0 & 1 & 2 & 3 \\
\hline Possible & $0.1 \%<\mathrm{P}<10 \%$ & 2 & 0 & 2 & 4 & 6 \\
\hline Likely & $\mathrm{P}>10 \%$ & 3 & 0 & 3 & 6 & 9 \\
\hline
\end{tabular}
consequence levels by exceedance levels leads to a risk level table for each movement, velocity and forces. The risk levels are given in Table 4.

Table 4. Risk levels.

\section{EARLY WARNING SYSTEM}

The warning system consists of two components: data evaluation and user interaction. Warnings are issued based on the forecast waves and atmospheric conditions as early as 72 hours prior to their occurrence.

In the data evaluation component, the system includes all relevant information for dangerous events identification and warning. This information consists of: the topography and bathymetry of the area; sea-wave forecasts and the characteristics of the berth and of the ship moored at the study area.

Based on risk levels, warnings are issued. In this work, five warning levels were defined as follows:

I. Risk level of 0 or 1 - No danger.

II. Risk level of 2 - Low warning level. Freight activity and loading and unloading operations conditioned.

III. Risk level of 3 or 4 - Moderate warning level. Loading and unloading operations cannot be performed.

IV. Risk level of 6 - High warning level. Loading and unloading operations cannot be performed. Possibility of breakage of mooring system elements.

V. Risk level of 9 - Maximum warning level. Loading and unloading operations are suspended. Possibility of breakage of mooring system elements. The infrastructure can be seriously damaged.

The results generated by the data evaluation and risk assessment components take different forms, namely, graphs, maps, and reports. These are then transmitted to the user interaction component to allow the issue of warnings.

The user interaction component is embodied in a Web application, in which all the warning system is parameterized. 
The web platform was created to allow viewing and analysis of results through user-friendly features, such that the results are easily read by the common user. In the Web platform, the results generated by the different numerical models are presented in various formats. All relevant results are presented statically through images, to be quickly and easily readable, even when the user has a limited or poor network access.

The web platform allows, in addition to the layouts, to view the sea-wave characteristics close to the ship position, the maximum values of the surge, sway, and yaw motion, as well as of forces in the mooring lines.

One can also view the warning levels issued for the study area in a specific date and time.

\section{TEST CASE APPLICATION}

For the first application of this module, a container ship, and a specific berth in the container terminal of the Praia da Vitória port were chosen. The bay and the port of Praia da Vitória are located on the east coast of Terceira Island, one of the nine islands of the Azores archipelago (Fig. 2).
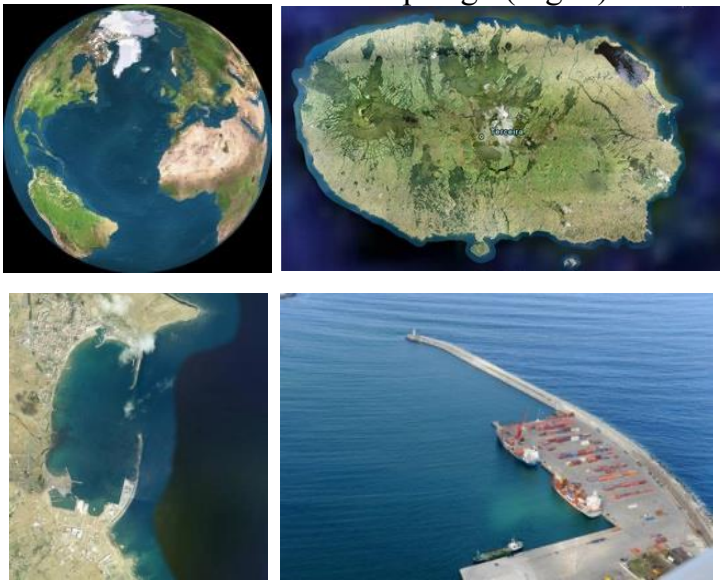

Fig. 2. Location and aerial views of the bay, port and container terminal of Praia da Vitória.

The bay coastline is characterized by the existence of a seawall and a groin field, with five groins rooted on the beach protection wall, in the central area in front of the gap between the jetties. These groins have different lengths and are deployed parallel to the WSW-ENE direction.

Two breakwaters protect the bay: the so-called north breakwater, which is $560 \mathrm{~m}$ long and houses the port facilities to support the Lajes Air Base; and the so-called south breakwater, which is $1300 \mathrm{~m}$ long and has a curved planform and houses the port facilities of the commercial sector and fisheries. This port is the second largest Azorean port infrastructure being surpassed only by the port of Ponta Delgada, in what concerns the number of ships and volume of handled cargo.

Benefiting from the shelter provided by the North breakwater, a marina was built by the Praia da Vitória Municipality, in the late 1990s, between Prainha and Praia
Grande. It has 210 berths, a reception pier and supporting infrastructure.

The application of SWAMS ALERT system to the port of Praia da Vitória is made every day and allows the prediction, 72 hours in advance, of sea-wave effects in terms of moored ships movements docked at the main berth (Berth 12).

To characterize the sea waves (Hs, Tm, Tp, $\theta \mathrm{m}$ ) off Praia da Victoria, the system uses, once a day, the WWIII sea-wave predictions (Tolman, 1999), for 72 hours with a 3-hour interval, which are provided by The Fleet Numerical Meteorology and Oceanography Center (FNMOC). For the study area, the WWIII model estimates are available with a resolution of $1^{\circ}$, since September 2003. The regional wind data required to run the SWAN model are also available from FNMOC through NAVGEM model (Whitcomb 2012), whereas the tidal data is provided by the XTide model. This astronomical tide prediction model has tide information from 1700 to 2100 .

Given the WWIII model results the values at the points closer to Terceira Island are used as the boundary conditions for sea-wave propagation models. These values are transferred into the bay and port of Praia da Vitória using two models for seawave propagation and deformation: the SWAN model and the DREAMS model. The use of models and their application conditions are described in Neves et al. (2012). Fig. 3 presents the layouts generated by the warning system for DREAMS model results. Wave directions and significant wave heights, Hs are represented in a graphical way in order to be simple to interpret.

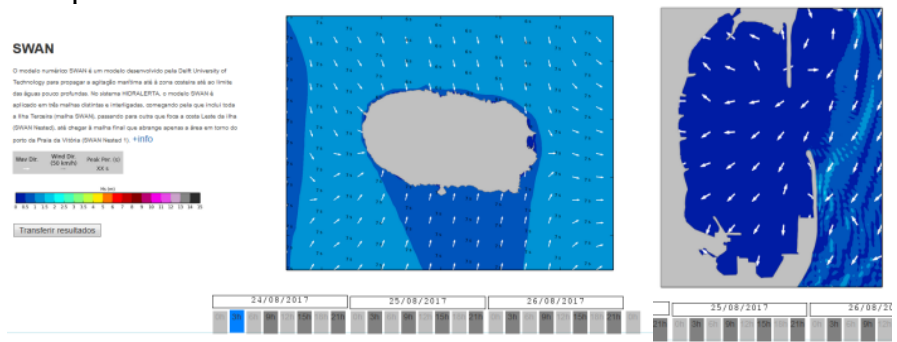

Fig. 3. Example of a layout generated for SWAN (left) and DREAMS (right) model's results.

For the application of WAMIT and BAS models, it is necessary to define the characteristics of the vessel and mooring system. The methodology is described in Pinheiro et al. (2015).

The studied ship is a generic container with a displaced volume of $12,717 \mathrm{~m}^{3}$, a length in the floating area of $120 \mathrm{~m}$, a beam of $19 \mathrm{~m}$ and a draft of $8 \mathrm{~m}$. The vessel is moored in a $10 \mathrm{~m}$ water depth dock. The hull form was discretized with 3464 rectangular and triangular panels as shown in Fig. 4. 


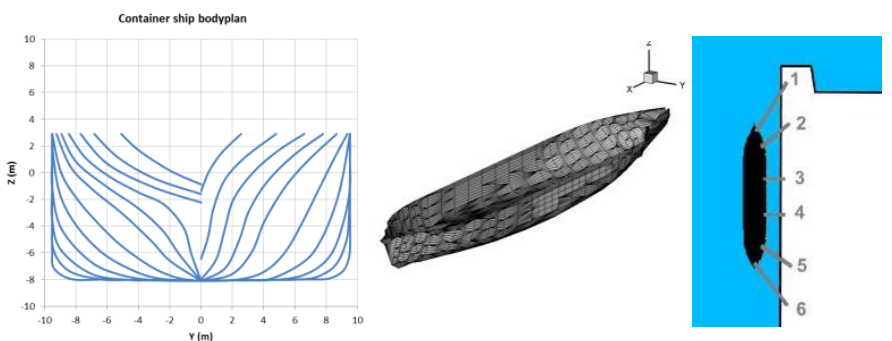

Fig. 4. Body plan and panelling of the container ship's hull.

Fig. 4 also shows the mooring system configuration in which the ship is moored to the berth by 6 mooring lines (1 lay line at bow and another at stern, and four breast lines). The contact between the ship and the quay is prevented by five pneumatic fenders. The same constitutive relations were considered for all mooring lines: linear range from $0 \mathrm{kN}$ to 931 $\mathrm{kN}$ maximum load, which corresponds to an elongation of $8 \%$. The constitutive relation for the fenders is also linear with a maximum compression force $4900 \mathrm{kN}$ for a deflection of $1 \mathrm{~m}$.

In this case, a wave field with $\mathrm{Hs}=0,4 \mathrm{~m}, \mathrm{Tp}=8,1 \mathrm{~s}$ and $45^{\circ}$ wave angle of attack was simulated to illustrate the results.

In Fig. 5, an example of the time series of wave induced forces in mooring line ML4 is presented. The dashed horizontal lines represent the pre-set limits for mooring line forces. In Fig. 6 , the Power spectral density of forces in mooring line ML4 is presented. Using eq. 7 the exceedance probability curve provides information on any thresholds, Fig. 7.

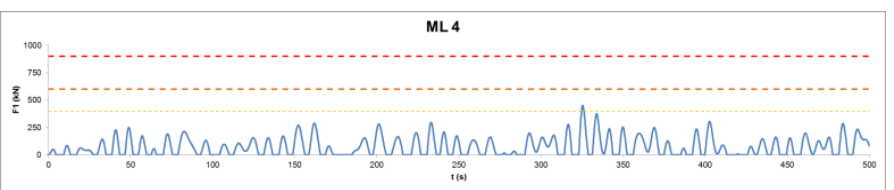

Fig. 5. Time series of wave induced forces in mooring line 4.

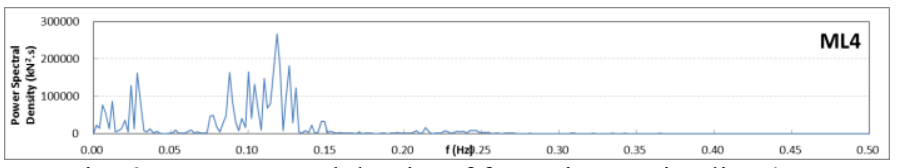

Fig. 6. Power spectral density of forces in mooring line 4.

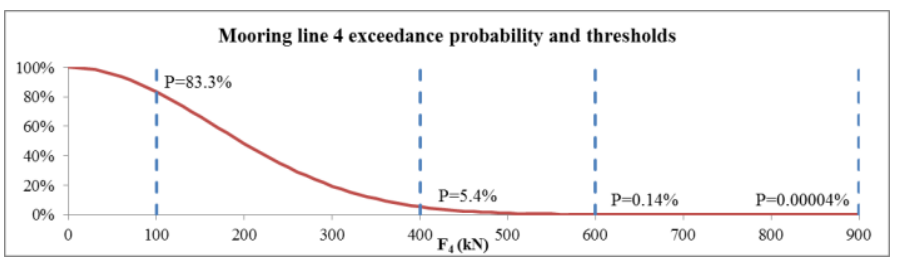

Fig. 7. Mooring line ML4 exceedance probability curve and thresholds.

Table 5. Risk levels of mooring line ML4 forces.

\begin{tabular}{lllll}
\hline Consequence & insignificant & Mild & Serious & Critical \\
\cline { 2 - 5 } Thresholds & $>100 \mathrm{kN}$ & $>400 \mathrm{kN}$ & $>600 \mathrm{kN}$ & $>900 \mathrm{kN}$ \\
\hline Exceedance Prob. & $83.3 \%$ & $5.4 \%$ & $0.14 \%$ & $0.0 \%$ \\
\hline Consequence level & 0 & 1 & 2 & 3 \\
\hline Prob. Level & 3 & 2 & 2 & 0 \\
\hline Risk level & 0 & 2 & 4 & 0 \\
\hline
\end{tabular}

The consequence threshold is then selected based on the one that produces the higher risk level. In this case (ML4) $600 \mathrm{kN}$ threshold with an exceedance probability of $0.14 \%$ produces a risk level of 4 , Table 5 .

Using all this information the warnings levels are determined and, the compacted results for all mooring lines are presented in Table 6 and Table 7.

Table 6. Statistical analysis of mooring lines forces $(\mathrm{kN})$.

\begin{tabular}{lllllll}
\hline & ML1 & ML2 & ML3 & ML4 & ML5 & ML6 \\
\hline$\overline{\boldsymbol{F}}$ & 19 & 96 & 100 & 104 & 60 & 21 \\
\hline $\mathrm{F}_{\text {rms }}$ & 25 & 123 & 127 & 133 & 76 & 27 \\
\hline $\mathrm{F}_{\mathrm{s}}$ & 35 & 174 & 180 & 188 & 108 & 39 \\
\hline $\mathrm{F}_{1 / 10}$ & 44 & 221 & 229 & 239 & 138 & 49 \\
\hline $\mathrm{F}_{1 / 100}$ & 58 & 290 & 301 & 314 & 180 & 64 \\
\hline $\mathrm{F}_{\max }$ & 65 & 380 & 447 & 451 & 205 & 72 \\
\hline
\end{tabular}

Table 7. Warning levels of mooring line forces.

\begin{tabular}{lllllll}
\hline $\begin{array}{l}\text { Mooring Line } \\
\text { Force }\end{array}$ & ML1 & ML2 & ML3 & ML4 & ML5 & ML6 \\
\hline Threshold (kN) & 100 & 400 & 600 & 600 & 400 & 100 \\
\hline Exc. Prob. (\%) & $0.48 \%$ & $3.33 \%$ & $0.08 \%$ & $0.14 \%$ & $0.01 \%$ & $1.34 \%$ \\
\hline Risk level & 0 & 2 & 2 & 4 & 1 & 0 \\
\hline Warning level & I & II & III & III & I & I \\
\hline
\end{tabular}

Finally, Fig. 8 presents the layout of the mooring line forces warning map generated by the system.

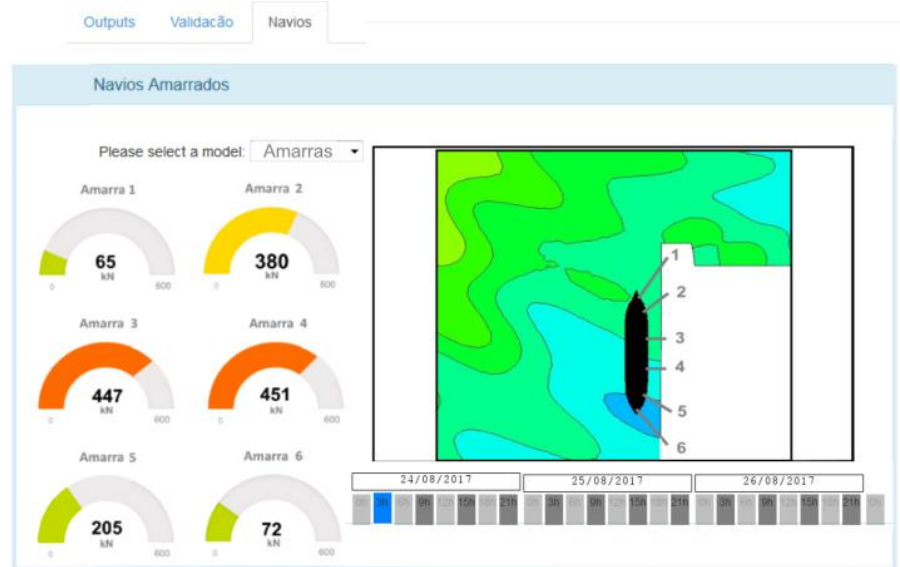

Fig. 8. Layout of the mooring line forces warning map generated by the system.

The same analysis is made for movements and velocities, the compacted results are given from Table 8 to Table 11.

Table 8. Statistical analysis of six degrees of freedom movements of the moored ship.

\begin{tabular}{lllllll}
\hline & $\begin{array}{l}\text { Surge } \\
(\mathrm{m})\end{array}$ & $\begin{array}{l}\text { Sway } \\
(\mathrm{m})\end{array}$ & $\begin{array}{l}\text { Heave } \\
(\mathrm{m})\end{array}$ & $\begin{array}{l}\text { Roll } \\
(\boldsymbol{\circ})\end{array}$ & $\begin{array}{l}\text { Pitch } \\
\left({ }^{\circ}\right)\end{array}$ & $\begin{array}{l}\text { Yaw } \\
\left({ }^{\circ}\right)\end{array}$ \\
\hline$\overline{\boldsymbol{X}}$ & 1.26 & 1.25 & 0.16 & 6.70 & 0.99 & 2.56 \\
\hline $\mathrm{X}_{\mathrm{rms}}$ & 1.61 & 1.61 & 0.21 & 8.57 & 1.26 & 3.27 \\
\hline $\mathrm{X}_{\mathrm{s}}$ & $\mathbf{2 . 2 8}$ & $\mathbf{2 . 2 7}$ & 0.30 & 12.14 & $\mathbf{1 . 7 9}$ & 4.63 \\
\hline $\mathrm{X}_{1 / 10}$ & 2.90 & 2.89 & 0.38 & 15.43 & 2.27 & 5.89 \\
\hline $\mathrm{X}_{1 / 100}$ & 3.80 & 3.79 & 0.50 & 20.23 & 2.98 & 7.72 \\
\hline $\mathrm{X}_{\max }$ & 4.10 & 4.09 & 0.54 & 21.85 & 3.22 & 8.34 \\
\hline
\end{tabular}


Table 9. Warning levels for six degrees of freedom movements of the moored ship.

\begin{tabular}{lllllll}
\hline & Surge & Sway & Heave & Roll & Pitch & Yaw \\
\hline Threshold $\left(\mathrm{m} \mathrm{or}^{\circ}\right)$ & 0.5 & 0.3 & 0.4 & 1.5 & 0.5 & 0.5 \\
\hline Exc. Prob. $(\%)$ & $88.3 \%$ & $95.6 \%$ & $1.0 \%$ & $96.1 \%$ & $81.7 \%$ & $97.0 \%$ \\
\hline Risk level & 9 & 9 & 6 & 9 & 9 & 9 \\
\hline Warning level & $\mathrm{V}$ & $\mathrm{V}$ & $\mathrm{IV}$ & $\mathrm{V}$ & $\mathrm{V}$ & $\mathrm{V}$ \\
\hline
\end{tabular}

Table 10. Statistical analysis of six degrees of freedom velocities of the moored ship.

\begin{tabular}{lcccccc}
\hline & $\begin{array}{c}\text { Surge } \\
(\mathrm{m} / \mathrm{s})\end{array}$ & $\begin{array}{c}\text { Sway } \\
(\mathrm{m} / \mathrm{s})\end{array}$ & $\begin{array}{c}\text { Heave } \\
(\mathrm{m} / \mathrm{s})\end{array}$ & $\begin{array}{c}\text { Roll } \\
(\% / \mathrm{s})\end{array}$ & $\begin{array}{c}\text { Pitch } \\
(\% / \mathrm{s})\end{array}$ & $\begin{array}{c}\text { Yaw } \\
(\% / \mathrm{s})\end{array}$ \\
\hline$\overline{\boldsymbol{U}}$ & 0.20 & 0.14 & 0.11 & 2.09 & 0.74 & 0.58 \\
\hline $\mathrm{U}_{\text {rms }}$ & 0.25 & 0.17 & 0.14 & 2.68 & 0.95 & 0.74 \\
\hline $\mathrm{U}_{\mathrm{s}}$ & $\mathbf{0 . 3 6}$ & 0.25 & 0.20 & 3.79 & 1.34 & 1.04 \\
\hline $\mathrm{U}_{1 / 10}$ & 0.45 & 0.31 & 0.25 & 4.82 & 1.70 & 1.33 \\
\hline $\mathrm{U}_{1 / 100}$ & 0.60 & 0.41 & 0.33 & 6.32 & 2.23 & 1.74 \\
\hline $\mathrm{U}_{\max }$ & 0.64 & 0.44 & 0.36 & 6.83 & 2.41 & 1.88 \\
\hline
\end{tabular}

Table 11. Warning levels for six degrees of freedom velocities of the moored ship.

\begin{tabular}{llll|lll}
\hline & Surge & Sway & Heave & Roll & Pitch & Yaw \\
\hline Threshold $(\mathrm{m} / \mathrm{s}$ or $\%)$ & 0.60 & 0.45 & 0.60 & 2.00 & 2.00 & 2.00 \\
\hline Exc. Prob. $\%)$ & $1.7 \%$ & $0.02 \%$ & $38.7 \%$ & $48.8 \%$ & $0.3 \%$ & $0.008 \%$ \\
\hline Risk level & 4 & 2 & 9 & 9 & 6 & 3 \\
\hline Warning level & III & II & V & V & IV & III \\
\hline
\end{tabular}

Fig. 9 presents the movements warning map generated by the system.

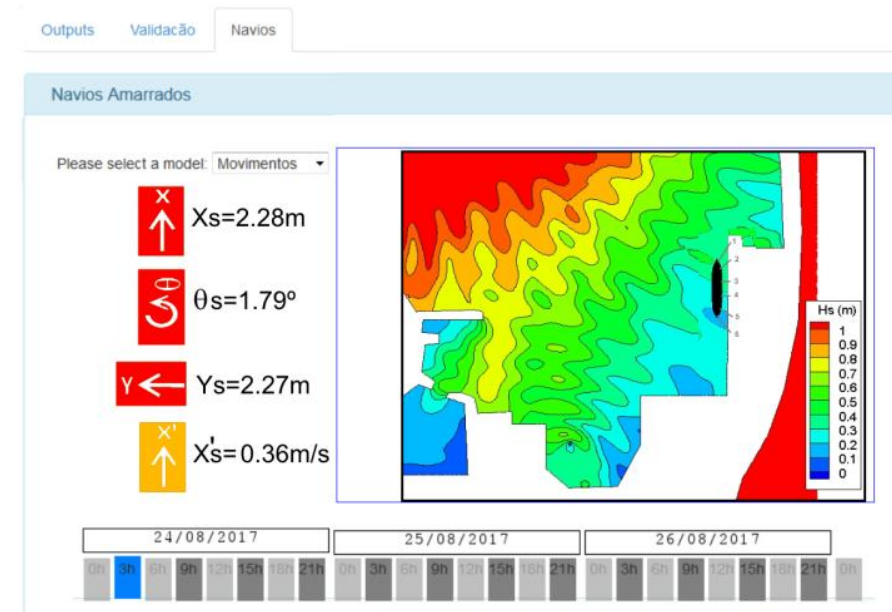

Fig. 9. Layout of the movements warning map generated by the system.

\section{CONCLUSIONS}

The availability of sea-wave forecasts offshore combined with the use of adequate numerical models for sea-wave propagation can produce daily forecasts of potentially hazardous sea-wave effects in port structures, moored ships and port activities. With this purpose a new alert system was set-up, SWAMS ALERT. This system follows a concept that is fully customizable to the requirements of any given port and ship.
The illustrated case study on the bay port area of Praia da Vitória showcased the outputs of such a system and the issuing of warnings using a user-friendly web based application.

The collaboration of local authorities is of paramount importance in the fine tuning of the system, namely in the establishment of the consequences table for ship-related operational costs that is required in module IV for the assessment of risk associated with excessive moored ship motions.

This is an innovative, interactive, flexible, scalable and user-friendly Web information system that can be easily tailored to the needs of port stakeholders. Innovation in this system resides on being based on quantities of direct relevance for ship safety namely ship movements and forces on mooring system. Knowledge of those quantities if of paramount importance to better target emergency plans.

This is a major change with relation to the usual information systems for the safety of port operations that are based solely on sea-wave characteristics (wave height and wave period).

The system has the potential to be continuously optimised. Every event will serve as a learning experience and the recorded data can be used to improve forecasting models, adjust sensor positioning and provide insight on the causes, evolution and frequency of extreme weather events.

\section{ACKNOWLEDGEMENTS}

This work is a contribution from HIDRALERTA project "Forecasting System and Flood Warning in Coastal and Port Areas" (PTDC/AAC-AMB/120702/2010) and M\&MSHIPS project "Manoeuvring \& Moored SHIPS in ports" (PTDC/EMSTRA/5628/2014) funded by the Foundation for Science and Technology of the Portuguese Government. The authors thank the collaboration of local authorities (Municipality of Praia da Vitoria, Azores Ports, Regional Service of Civil Protection, and Fire Azores).

\section{REFERENCES}

Booij, N., Ris, R. C., and Holthuijsen, L. H., 1999, A Third-Generation Wave Model for Coastal Regions, Part I, Model Description and Validation, Journal of Geographical Research, Vol. 104, Issue C4, pp. 7649-7666.

Chang, C.-H.; Xu, J.; Song, D.-P., 2014, An analysis of safety and security risks in container shipping operations: A case study of Taiwan, Safety Science, Volume 63, Pages 168178, ISSN 0925-7535.

Elzinga, T., Iribarren, J. R., Jensen O. J., 1992, Movements of moored ships in harbors, Proc. 23rd International Conference on Coastal Engineering, ASCE, pp. 3216-3229.

Faber, M. H. 2007. Risk and Safety in Civil Engineering. Lecture Notes. Prof. Dr. M. H. Faber. ETH Swiss Federal Institute of Technology Zurich. 
Fortes, C.J.E.M., 2002, Transformações Não Lineares de Ondas em Zonas Portuárias, Análise pelo Método dos Elementos Finitos, Tese de Doutoramento em Eng. Mecânica, IST.

Husdal, J., Bråthen, S., 2010. Bad locations, bad logistics? How Norwegian freight carriers handle transportation disruptions. In: The World Conference for Transportation Research 2010, Lisbon, Portugal, 11-15 July.

IMO, 2012. Guide to maritime Security \& ISPS Code. International Maritime Organization, London.

IMO. ISM Code and Guidelines International Maritime Organization, London (2010).

Korsemeyer F.T., Lee C.-H., Newman J.N., Sclavounos P.D., 1988, The analysis of wave effects on tension-leg platforms, 7th International Conference Offshore Mechanics and Arctic Engineering, Houston, Texas, pp. 1-14.

Longuet-Higgins M.S., 1952, On the statistical distribution of the heights of sea waves. J. Marine Research, Vol XI , No. 3.

Mokhtari, K., Ren, J.; Roberts, C.; Wang, J., 2012, Decision support framework for risk management on sea ports and terminals using fuzzy set theory and evidential reasoning approach, Expert Systems with Applications, Volume 39, Issue 5, Pages 5087-5103, ISSN 0957-4174.

Mynett, A.E., Keunig, P.J.,Vis, F.C., 1985, The dynamic behaviour of moored vessels inside a harbour configuration, Int. Conf. on Numerical Modelling of Ports and Harbours, Birmingham, England: 23-25 April 1985. Cranfield: BHRA, The Fluid Engineering Centre.

Neves, D.R., Santos, J.A., Reis, M.T., Fortes, C.J.E.M., Simões, A., Azevedo, E.B., Rodrigues, M.C., 2012, Metodologia de avaliação do risco associado ao galgamento de estruturas marítimas. Aplicação ao porto e à baía da Praia da Vitória, Açores, Portugal, Journal of Integrated Coastal Zone Management, 123, 291-312.

Notteboom T.E., 2006, The time factor in liner shipping services. Maritime Economics and Logistics, 8 (1) (2006), pp. 19-39.

OCIMF, 1992, Mooring equipment guidelines, Witherby e Co. Ltd.

PIANC, 1995, Criteria for movements of moored ships in harbors, Technical report Permanent International Association of Navigation Congresses PIANC Supplement to bulletin no. 88 .

PIANC. 2012 Guidelines for berthing structures related to thrusters, PIANC, Brussels, Belgium.

Pinheiro, L.V., Fortes, C.J.E.M., Santos, J.A., Fernandes, L., Walkley, M., 2012, Boussinesq-Type Numerical Model for Wave Propagation Near Shore and Wave Penetration In Harbors. Maritime Engineering and Technology - Guedes Soares et al. Taylor \& Francis Group, London, ISBN 978-0415-62146-5.

Pinheiro, L.V., Fortes, C.J.E.M., Abecasis Jalles, B.M, Santos, J.A., 2015, Simulation of wave action on a moored container carrier inside Sines' Harbour. Maritime Technology and Engineering - Guedes Soares \& Santos (Eds) Taylor \& Francis Group, London, ISBN 978-1-138-02727-5.
Raposeiro P.D, Fortes, C.J.E.M., Reis, M.T. e Ferreira, J.C., 2010, Development of a methodology to evaluate the flood risk at the coastal zone, In Geographic Technologies Applied to Marine Spatial Planning and Integrated Coastal Zone Management, Calado, H. e Gil, A. Eds., University of The Azores Ponta Delgada, August, 129-137. ISBN: 978-972-861264-1.

Sabino, A., Rodrigues, A., Poseiro, P., Reis, M.T., Fortes, C.J.E.M., Reis, R., 2015, Coastal risk forecast system, In Proc. GISTAM 2015, 1st International Conference on Geographical Information Systems Theory, Applications and Management, C. Grueau \& J.G. Rocha Eds., SCITEPRESS, 201-209. ISBN: 978-989-758-099-4

Santos, J.A., 1994, MOORNAV - Numerical model for the behaviour of moored ships, Final report, Lisbon: Report 3/94B, Projecto NATO PO-Waves.

Talley, W.K., 1996, Determinants of cargo damage risk and severity: the case of containership accidents. Logistics and Transportation Review, 32 (4) (1996), pp. 377-388

Taubenblock, H. Post, J. Roth A., Zosseder K., Strunz G., and Dech S. 2008. A conceptual vulnerability and risk framework as outline to identify capabilities of remote sensing. Nat. Hazards Earth Syst. Sci., 8, 409-420.

Tolman, H., 1999, User Manual and System Documentation of WAVEWATCH-III, Version 1.18, NOA/NWS/NCEP/OMB, Technical Note 166, Washington, E.U.A.

Wang, J. Li, Mi. Liu, Y. Zhang H., Zou. W., Cheng L., 2014, Safety assessment of shipping routes in the South China Sea based on the fuzzy analytic hierarchy process Safety Science, 6 (2014), pp. 46-57.

Ward, S., 2005, Risk management: organisation and context, London, GB, Witherby Insurance \& Legal, 222pp.

Whitcomb, T., 2012, Navy global forecast system, NAVGEM: Distribution and user support, In: Proceedings of the 2nd Scientific Workshop on ONR DRI: Unified Parameterization for Extended Range Prediction.

Yip, T. L., 2008, Port traffic risks - A study of accidents in Hong Kong waters, Transportation Research Part E: Logistics and Transportation Review, Volume 44, Issue 5, 2008, Pages 921-931, ISSN 1366-5545 